\title{
Is narrow-band imaging a useful tool in screening colonoscopy performed by an experienced endoscopist? A prospective randomised study on 533 patients
}

\author{
Marcin Romańczyk ${ }^{1}$, Tomasz Romańczyk ${ }^{1}$, Hubert Bołdys ${ }^{1}$, Mateusz Koziej², Krzysztof Jarus ${ }^{1}$ \\ ${ }^{1} \mathrm{H}-\mathrm{T}$. Centrum Medyczne-Endoterapia, Tychy, Poland \\ ${ }^{2}$ Department of Anatomy, Jagiellonian University Medical College, Krakow, Poland
}

Gastroenterology Rev 2018; 13 (3): 206-212

DOI: https://doi.org/10.5114/pg.2018.78286

Key words: cancer screening, colonoscopy, narrow band imaging.

Address for correspondence: Marcin Romańczyk MD, H-T. Centrum Medyczne-Endoterapia, al. Bielska 105, 43-100 Tychy, Poland, phone: +48 3221788 66, fax: +48 3221753 60, e-mail: marcin.romanczyk@gmail.com

\begin{abstract}
Introduction: The detection of adenomas is the basic goal for colorectal cancer screening programs; therefore, every possibility to improve the adenoma detection rate is valuable.

Aim: To answer the question of whether narrow-band imaging (NBI) can enhance detection quality in screening for colonoscopy.

Material and methods: A group of 533 patients (202 men: 331 women; average age: 56.1 years) included in a colorectal cancer screening program were randomised into two groups (NBI $n=266$ and white light (WL) $n=267$ ). Five hundred and twentyseven patients were finally included in the assessment. Examinations were performed by three experienced colonoscopists. The NBI was used only at the withdrawal of the instrument.

Results: Comparing WL and NBI colonoscopies, differences in the mean number of detected polyps per patient $(1.36 \pm 2.79$ WL vs. $1.65 \pm 2.11 \mathrm{NBI} ; p=0.012$ ), polyp detection rate (PDR) (48.5\% WL vs. $57.2 \% \mathrm{NBI} ; p=0.049)$, PDR for polyps $\leq 5 \mathrm{~mm}(44.7 \%$ WL vs. $54 \% \mathrm{NBI} ; p=0.033$ ), and PDR for left-sided polyps ( $43.3 \% \mathrm{WL}$ vs. $52.7 \% \mathrm{NBI} ; p=0.033$ ) were observed. The difference in adenoma detection rate (ADR) as well as in adenomas/patient was not significant. Narrow-band imaging enhanced significantly one of three operators' ADR (15.6\% WL vs. $25.7 \% \mathrm{NBI} ; p=0.038)$.

Conclusions: It seems that NBI improves only detection of hyperplastic polyps, especially those that are diminutive and left-sided. However, after analysis of particular endoscopists, it can clearly be seen that some of them may benefit from NBI.
\end{abstract}

\section{Introduction}

Colorectal cancer (CRC) is still one of the most common causes of cancer and cancer-related death worldwide [1]. Therefore, it is still necessary to improve prevention, screening, and treatment processes. Screening colonoscopy with polypectomy gives a great possibility to avoid CRC by removing adenomas that are pre-cancerous lesions [2]. Despite the fact that the adenoma detection rate (ADR) is a well-known tool for quality measurement of colonoscopy [3], it may vary, depending on the colonoscopist, from $7.4 \%$ to $52.5 \%$ [4]. The fact that, as mentioned above, there is a $22 \%$ polyp miss rate and $26 \% 1-5 \mathrm{~mm}$ adenoma miss rate
[5] demands a constant search for improvement in polyp and adenoma detection. For that reason, multiple devices were invented to help enhance adenoma detection [6]. Narrow-band imaging is a visual system provided by an optical filter $415 \mathrm{~nm}$ for blue and $540 \mathrm{~nm}$ for green light, which enhances visibility of mucosal vessels due to absorption of haemoglobin. Despite a number of trials in this field [7-17], a lack of data is observed, especially in the homogenous population for screening colonoscopy performed in the same conditions, which can answer the question of whether narrow-band imaging (NBI) can improve the quality of detection in comparison to classic colonoscopy examination. 


\section{Aim}

The aim of the study was to verify if NBI can help experienced endoscopists to improve their detection indicators.

\section{Material and methods}

\section{Study design and patients}

This was a prospective, randomised study conducted from 22/JUN/2007 until 4/DEC/2007, approved by the Silesian Ethics Commission, conducted in accordance with the Declaration of Helsinki. Written, informed consent was obtained from all patients. Patients were recruited from the national colorectal cancer screening programme. The programme inclusion criteria were: age $50-65$ or $40-65$ years if CRC occurred in a first-degree relative, without any symptoms such as gastrointestinal bleeding, diarrhoea or constipation during last months with unknown cause, body mass loss, anaemia with unknown cause, and without colonoscopy performed in the last 10 years. Patients with inflammatory bowel disease were not included in the screening programme. The sample size was estimated assuming that the increase of ADR from approx. 18\%, which was known in our centre, to $30 \%$ requires at least 198 patients for each group with $80 \%$ statistical power and a significance level of 0.05 (two-sided). The primary outcome measure was the adenoma detection rate (ADR). The secondary outcome measure included: number of adenomas, mean number of adenomas per patient, ADR for left and right-sided adenomas, polyp detection rate (PDR), number of polyps, mean number of polyps per patient, PDR for right and left-sided polyps, number of polyps $<5 \mathrm{~mm}$, and PDR for polyps $<5 \mathrm{~mm}$. A group of 533 individuals (202 men, 331 women; average age: 56.1 years) included in the colorectal cancer screening programme was randomised into two groups in a $1: 1$ ratio by using a randomisation list (NBI $n=266$ and white light $(\mathrm{WL}) n=267)$.

\section{Colonoscopy}

Individuals were prepared with four litres of polyethylene glycol solution in split doses. If the examination was performed before 12 a.m., half of the solution was taken the day before the examination. Patients were sedated or consciously premedicated with midazolam $1 \mathrm{mg}$ and fentanyl $50 \mu \mathrm{g}$ depending on the individual's preference. All examinations were performed at H-T Centrum Medyczne-Endoterapia Tychy, Poland by three experienced colonoscopists ( $>$ 10,000 colonoscopies performed by each), who were familiar with NBI imaging. Bowel preparation was described as good, fair, or poor. $\mathrm{Pa}$ tients with good or fair bowel preparation were included in the assessment. Colonoscopies were performed using EVIS EXERA II system colonoscopes (Q180AI).

Every examination was performed in WL during insertion, after reaching the caecum, patients were randomised into the WL or NBI group in a $1: 1$ ratio. The withdrawal time was neither measured nor estimated; however, in the colonoscopy protocol the time of withdrawal was at least $6 \mathrm{~min}$. In patients who were randomised to the NBI group, NBI was used during the whole drawing out procedure, apart from polypectomies, which were performed in WL. After polypectomy the examination was continued with NBI. Polyps were measured by opened forceps or a snare and removed by using a snare, hot biopsy, biopsy forceps, and mucosectomy. The location of polyps was described as "left-sided" if distal to splenic flexure or "right-sided" if proximal to splenic flexure. Patients who had polyps larger than $10 \mathrm{~mm}$ or needed preparation for polypectomy were not excluded from the assessment; however, only the polyps described in screening colonoscopy were included in the assessment after polypectomy and histopathological examination.

\section{Statistical analysis}

The data are presented as means with corresponding standard deviations (SD) or medians with the quartiles $\left(Q_{1}, Q_{3}\right)$ depending on whether normal distribution was present. The Shapiro-Wilk test was used to determine if the quantitative data was normally distributed. To verify the homogeneity of variance, Levene's test was performed. We also used Student's t-tests and the Mann-Whitney $U$ test for statistical comparisons between two groups. Kruskal-Wallis one-way analysis of variance with Bonferroni correction was performed to determine significant differences between operators. Statistical comparisons for categorical data were performed using the $\chi^{2}$ or Fisher exact tests. In this case the Bonferroni correction was applied to resolve the problem of multiple testing and of finding at least one significant result just due to chance. The significance level was set to be less than 0.0167; Graphs were generated to present the proportion of patients with polyps and adenoma rates per consecutive group, where one group was composed of 50 study participants. We performed statistical analyses with Statistica v12 (StatSoft Inc., Tulsa, OK, USA). A p-value of less than 0.05 was considered to be statistically significant.

\section{Results \\ Research in general}

A group of 533 patients (202 men and 331 women; average age: 56.15 years) included in the colorectal cancer screening programme were randomised into 


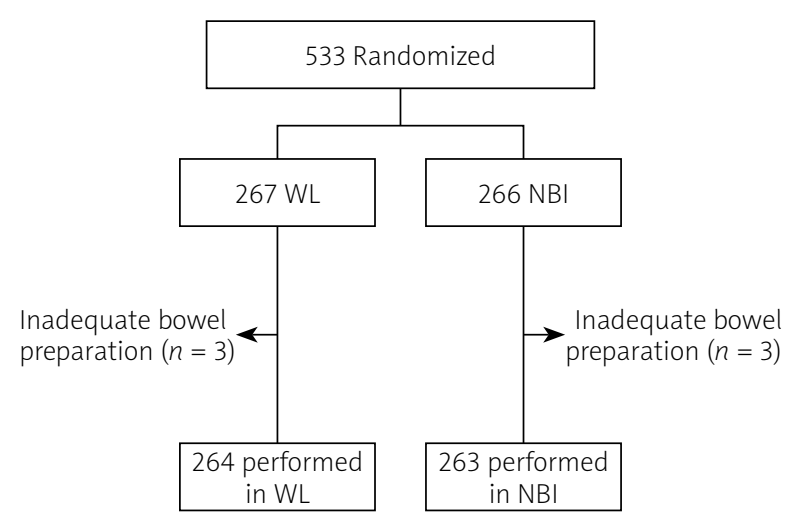

Figure 1. Subject enrolment

WL - White light, $\mathrm{NBI}$ - narrow-band imaging

two groups (NBI $n=266$ and $\mathrm{WL} n=267$ ). Five hundred and twenty-seven patients were finally included in the assessment; 6 patients were excluded (three NBI, three WL; 5 females, 1 male) due to inadequate bowel preparation (Figure 1). Caecum was reached in all colonoscopies; only one cancer occurred in hepatic flexure - we did not exclude this patient from assessment because caecum was reached. Differences in sex, age, and sedation rate were not significant (Table I). In the whole study 792 polyps were detected - 358 in the WL group and 434 in the NBI group; differences in PDR (48.5\% vs. $57.2 \% \mathrm{NBI} ; p=0.049$ ) and a mean number of polyps per patient $(1.36 \pm 2.79 \mathrm{WL}$ vs. $1.65 \pm 2.11 \mathrm{NBI} ; p=$ $0.012)$ were significant. Seven hundred and twenty-four of $792(91.4 \%)$ were diminutive polyps $(<5 \mathrm{~mm}) ; 318$ WL, 406 NBI. Narrow-band imaging enhanced significantly diminutive polyp detection (44.7\% WL vs. 54.0\% NBI, $p=0.033$ ). Six hundred and ninety polyps were located on the left side of the colon distal to splenic flexure ( $303 \mathrm{WL}$ vs. $387 \mathrm{NBI}$ ), and 102 were located on the right side ( $55 \mathrm{WL}$ vs. $47 \mathrm{NBI}$ ). The detection rate for left-sided polyps was significantly higher in the NBI group (44.3\% WL vs. $52.7 \% \mathrm{NBI}, p=0.033$ ) unlike right-sided polyps the difference was not statistically significant (12.9\% WL vs. $12.5 \% \mathrm{NBI}$ ). One hundred and eighty adenomas were detected -81 in the WL group and 99 in the NBI group. Adenoma detection rate (ADR) in the whole research was $21.25 \%$. There was no significant difference in ADR (19.31\% WL vs. $23.19 \% \mathrm{NBI}$ ) nor in the mean number of adenomas per patient $(0.3 \pm 0.80 \mathrm{WL}$ vs. $0.37 \pm 0.81$ $\mathrm{NBI}$ ). $\mathrm{NBI}$ enhanced detection of adenomas on the left side of the colon ( $57 \mathrm{WL}$ vs. $68 \mathrm{NBI}$ ) and on the right side (25 WL vs. $30 \mathrm{NBI}$ ); however, the differences in detection rates were not statistically significant. Eleven adenomas with high-grade dysplasia were found (8 WL vs. $3 \mathrm{NBI}$ ); the difference in detection rates was not significant. Only one cancer was found, in the NBI group. The statistics are shown in Table I.

\section{Learning effect}

The differences between the first 100 and last 100 colonoscopies performed (Table II) in PDR and ADR were not significant; however, a slight improvement of ADR in the NBI group was observed (21.0\% vs. 23.0\%). Graphic presentation of ADR and PDR during the studies is shown in Figures 2 and 3.

\section{Operator comparison}

A comparison of the operators is presented in Table III.

\section{Discussion}

Narrow-band imaging has been used successfully in endoscopy and in several studies [7-17] as well as meta-analyses $[16,18-20]$ that were conducted to determine whether this imaging technique improves the quality of colonoscopy. Data seem to be explicit about the influence of $\mathrm{NBI}$ on adenoma detection rates: it is not superior to standard imaging [7-11, 13, 15-20]. Our study also showed that the use of narrow-band imaging did not improve ADR in general. It only improved the detection of hyperplastic polyps, and it seems to be comparable to studies with a large number of patients included, conducted at that time - ADR obtained at $21 \%$ [7]. On the other hand, a recent tandem trial showed that ADR was significantly higher in HD-NBI vs. HD imaging [12].

Narrow-band imaging improved the number of detected adenomas located on the left side as well as on the right side of the colon; however, the differences were not significant. Higher right-sided adenoma detection would be desired to avoid right-sided CRC, which occurs more frequently after colonoscopy than in the general population [21].

Similarly to another study [17], we also did not observe any significant learning effect. The comparison of the first and last 100 examinations did not show any significant ADR improvement (as well as PDR). However, the ADR of the last 100 examinations was higher than first 100 colonoscopies ( $23 \%$ vs. $21 \%$ ). On the graphic presentation it is clear that a slightly growing trend is present in the NBI group. This suggests that some detection enhancement might exist when using NBI. Colonoscopies were performed by experienced colonoscopists (over 10,000 colonoscopies each) in one site, and the main colonoscopy quality indicator, the adenoma detection rate, did not vary among operators. Nevertheless, when more precise analyses were performed the differences among operators in ADR, PDR, polyps/patient, adenomas/patient in the white light imaging group occurred (Table III). On the other hand, this analysis may be affected by the fact that operator 3 had performed 
Table I. Comparison between white light (WL) and narrow-band imaging (NBI) groups

\begin{tabular}{|c|c|c|c|c|}
\hline Parameter & WL $(n=264)$ & $\mathrm{NBI}(n=263)$ & Total $(n=527)$ & $P$-value \\
\hline Male & 90 & 111 & 201 & 0.55 \\
\hline Female & 174 & 152 & 326 & \\
\hline Average age [years] & $55.8 \pm 5.0$ & $56.5 \pm 4.4$ & $56.1 \pm 4.7$ & 0.28 \\
\hline Sedation, $n(\%)$ & $23(8.7)$ & $14(5.3)$ & $37(7.0)$ & 0.13 \\
\hline \multicolumn{5}{|l|}{ Polyps: } \\
\hline All polyps & 358 & 434 & 792 & \\
\hline PDR & $48.5 \%$ & $57.2 \%$ & $55.0 \%$ & 0.049 \\
\hline Polyps/patient (SD) & $1.36(2.79)$ & $1.65(2.11)$ & $1.5(2.48)$ & 0.012 \\
\hline Polyps < $5 \mathrm{~mm}$ & 318 & 406 & 724 & \\
\hline $\mathrm{PDR}<5 \mathrm{~mm}$ & $44.7 \%$ & $54 \%$ & $49.3 \%$ & 0.033 \\
\hline Left-sided & 303 & 387 & 690 & \\
\hline PDR left-sided & $43.3 \%$ & $52.7 \%$ & $48 \%$ & 0.033 \\
\hline Right-sided & 55 & 47 & 102 & \\
\hline PDR right-sided & $12.9 \%$ & $12.5 \%$ & $12.7 \%$ & 0.89 \\
\hline \multicolumn{5}{|l|}{ Adenomas: } \\
\hline All adenomas & 81 & 99 & 180 & \\
\hline $\mathrm{ADR}$ & $19.31 \%$ & $23.19 \%$ & $21.25 \%$ & 0.27 \\
\hline Adenomas/patient (SD) & $0.30(0.81)$ & $0.37(0.81)$ & $0.34(0.81)$ & 0.42 \\
\hline Left-sided & 57 & 68 & 125 & \\
\hline ADR left-sided & $14.4 \%$ & $17.4 \%$ & $15.9 \%$ & 0.35 \\
\hline Right-sided & 25 & 30 & 55 & \\
\hline ADR right-sided & $6.5 \%$ & $8 \%$ & $7.2 \%$ & 0.51 \\
\hline HGD adenomas & 8 & 3 & 11 & \\
\hline ADR HGDA & $1.89 \%$ & $0.76 \%$ & $1.3 \%$ & 0.26 \\
\hline Cancer & 0 & 1 & 1 & - \\
\hline \multicolumn{5}{|l|}{ Operator 1: } \\
\hline PDR & $46.0 \%$ & $57.4 \%$ & & 0.07 \\
\hline ADR & $15.6 \%$ & $25.7 \%$ & & 0.038 \\
\hline Polyps/patient (SD) & $1.1(2.08)$ & $1.54(1.82)$ & & 0.015 \\
\hline Adenomas/patient (SD) & $0.19(0.49)$ & $0.43(0.89)$ & & 0.11 \\
\hline \multicolumn{5}{|l|}{ Operator 2: } \\
\hline PDR & $63.5 \%$ & $58.3 \%$ & & 0.56 \\
\hline ADR & $30.6 \%$ & $19.4 \%$ & & 0.09 \\
\hline Polyps/patient (SD) & $2.25(3.94)$ & $1.95(2.51)$ & & 0.74 \\
\hline Adenomas/patient (SD) & $0.6(1.22)$ & $0.31(0.74)$ & & 0.14 \\
\hline \multicolumn{5}{|l|}{ Operator 3: } \\
\hline PDR & $23.7 \%$ & $47.4 \%$ & & 0.13 \\
\hline$A D R$ & $7.9 \%$ & $26.3 \%$ & & 0.14 \\
\hline Polyps/patient (SD) & $0.32(0.62)$ & $0.74(0.99)$ & & 0.14 \\
\hline Adenomas/patient (SD) & $0.08(0.27)$ & $0.32(0.58)$ & & 0.25 \\
\hline
\end{tabular}

Polyps detection rate (PDR) - patients with at least one polyp, adenoma detection rate (ADR) - patients with at least one adenoma, SD - standard deviation, HGD - high-grade dysplasia, HGDA - high-grade dysplasia adenomas, polyps/patient - mean number of polyps per patient, adenomas/patient - mean number of adenomas per patient. 
Table II. Comparison of first 100 and last 100 colonoscopies performed in white light (WL) and narrowband imaging $(\mathrm{NBI})$

\begin{tabular}{lccc} 
Variable & First 100 & Last 100 & $P$-value \\
\hline PDR: & & \\
\hline WL & $49.0 \%$ & $46.0 \%$ & 0.67 \\
\hline $\mathrm{NBI}$ & $60.0 \%$ & $53.0 \%$ & 0.32 \\
\hline ADR: & & & \\
\hline $\mathrm{WL}$ & $19.0 \%$ & $19.0 \%$ & 1 \\
\hline $\mathrm{NBI}$ & $21.0 \%$ & $23.0 \%$ & 0.73
\end{tabular}

Polyp detection rate $(P D R)$ - patients with at least one polyp, adenoma detection rate $(A D R)$ - patients with at least one adenoma.

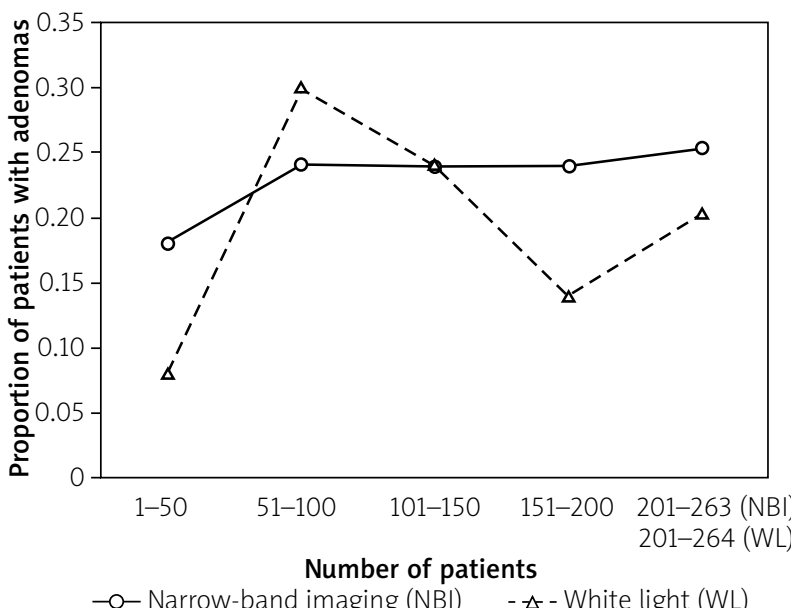

Ch-band imaging (NBI) - $₫$ -

Figure 3. Changes of proportion of patients with adenomas during study

a small number of colonoscopies in that study. Despite non-significant results, ADR can vary from $14 \%$ to $24.3 \%$ even when colonoscopies were performed in comparable conditions and with similar equipment by experienced specialists. Data from the Polish CRC screening programme showed a median ADR of $12.2 \%$ [3]; however, a recent population-based randomised clinical trial showed a mean ADR of $30.6 \%$ (newer equipment may affect that figure) [22]. Interesting results show analysis of every operator. Operator 1 , who had performed the largest number of colonoscopies in this study, benefited from using NBI, and, surprisingly, the differences were significant. Operator 2 in this study had the highest ADR (24.3\%), and despite non-significant differences, NBI decreased the ADR by $11.2 \%$ (30.6\% WL vs. $19.4 \% \mathrm{NBI}$ ). In addition, he had better PDR polyps/patient and adenomas/patient ratings at standard imagination. Operator 3 also benefited from NBI (ADR 7.9\% WL vs. 26.3\% $\mathrm{NBI}$ ); however, the number of colonoscopies performed in this study (57) may affect this. This analysis suggests

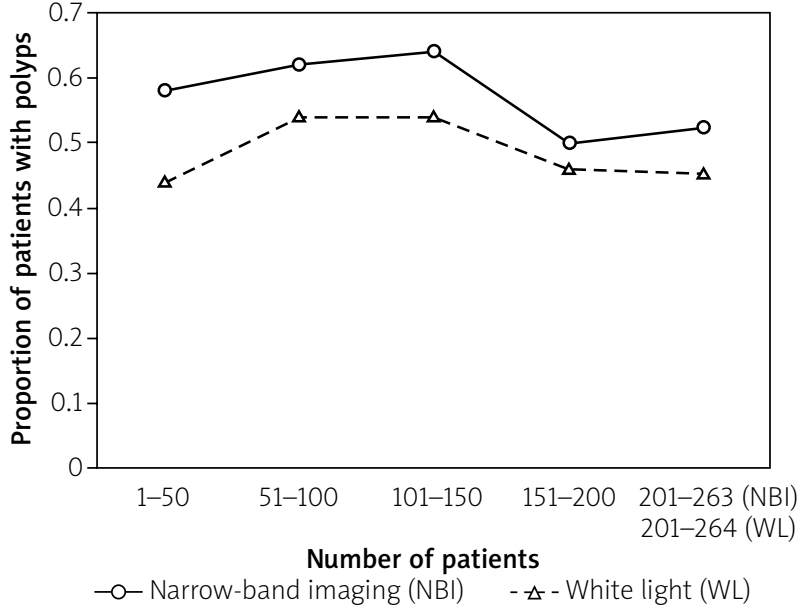

Figure 2. Changes of proportion of patients with polyps during the study

that examinations performed in WL are enough to reach a high adenoma detection rate. On the other hand, in white light imaging differences in ADR among operators were significant, and in the NBI group two of the three operators improved the ADR. Therefore, differences in ADR were not significant. A similar outcome was shown in another study; however, it was conducted on patients with high risk of adenomas, not in a general screening population [10].

This makes it possible to suggest that expertise in $\mathrm{NBI}$ might upgrade the quality of colonoscopy and improve the quality of lesion detection in centres with differences in ADR between operators. These statements create the hypothesis that the personalisation of colonoscopy technique by using $\mathrm{NBI}$ is not a firm recommendation or guideline but may have the desired result in upgrading the quality of colonoscopy. Such a case pertains particularly to experienced endoscopists who have not reached the desired ADR level, and it should not be used for trainees.

This study has several limitations: firstly, colonoscopies were performed in 2007 using the EXCERA II system on non-HD endoscopes. Meta-analysis shows differences in ADR of 3.5\% between WL and WL-HD [23], and now the European Society of Gastrointestinal Endoscopy (ESGE) recommend use of high-definition endoscopes [24]. Secondly, the EXCERA II NBI system is known to be darker than the current EXCERA III, which may lead to indirect translation between previous and current NBI systems. Also, the study was conducted by three experienced endoscopists, so the results are related to clinicians who have performed a vast number of colonoscopies.

\section{Conclusions}

Our results regarding routine use of NBI by experienced operators during screening colonoscopy show no 
Table III. Comparison of operators

\begin{tabular}{|c|c|c|c|c|}
\hline Variable & Operator 1 & Operator 2 & Operator 3 & $P$-value \\
\hline \multicolumn{5}{|l|}{ Total: } \\
\hline Coloscopies & 277 & 193 & 57 & \\
\hline Polyps/patient (SD) $)^{\star, * *, * \star *}$ & $1.31(1.97)$ & $2.08(3.21)$ & $0.46(0.78)$ & $<0.001$ \\
\hline Adenomas/patient (SD) & $0.31(0.73)$ & $0.44(0.99)$ & $0.16(0.41)$ & 0.14 \\
\hline $\mathrm{PDR}^{++,+++}$ & $51.6 \%$ & $60.6 \%$ & $31.6 \%$ & \\
\hline ADR & $20.6 \%$ & $24.3 \%$ & $14.0 \%$ & \\
\hline \multicolumn{5}{|l|}{ WL: } \\
\hline Coloscopies & 141 & 85 & 38 & \\
\hline Polyps/patient (SD) $)^{\star, \star * \star}$ & $1.1(2.08)$ & $2.25(3.94)$ & $0.32(0.62)$ & $<0.001$ \\
\hline Adenomas/patient (SD) $)^{\star \star \star * \star}$ & $0.19(0.49)$ & $0.6(1.22)$ & $0.08(0.27)$ & 0.95 \\
\hline $\mathrm{PDR}^{+,+++}$ & $46 \%$ & $63.5 \%$ & $23.7 \%$ & \\
\hline $\mathrm{ADR}^{+,+++}$ & $15.6 \%$ & $30.6 \%$ & $7.9 \%$ & \\
\hline \multicolumn{5}{|l|}{ NBI: } \\
\hline Coloscopies & 136 & 108 & 19 & \\
\hline Polyps/patient (SD) & $1.54(1.82)$ & $1.95(2.51)$ & $0.74(0.99)$ & 0.15 \\
\hline Adenomas/patient (SD) & $0.43(0.89)$ & $0.31(0.74)$ & $0.32(0.58)$ & 0.50 \\
\hline PDR & $57.4 \%$ & $58.3 \%$ & $47.4 \%$ & \\
\hline ADR & 25.7 & $19.4 \%$ & $26.3 \%$ & \\
\hline
\end{tabular}

Polyp detection rate $(P D R)$ - patients with at least one polyp, adenoma detection rate (ADR) - patients with at least one adenoma, polyps/patient - mean number of polyps per patient, adenomas/patient - mean number of adenomas per patient in white light (WL) and narrow-band imaging (NBI), SD - standard deviation. ${ }^{*} p<0.05$ in 1 and 2 operators comparison, ${ }^{* *} p<0.05$ in 1 and 3 operators comparison, ${ }^{* * *} p<0.05$ in 2 and 3 operators comparison. Results are considered statistically significant at $p<0.0167$ to allow for a Bonferroni correction, accounting for multiple comparisons: ${ }^{+} p<0.0167$ in 1 and 2 operators comparison, ${ }^{++} p<0.0167$ in 1 and 3 operators comparison, ${ }^{+++} p<0.0167$ in 2 and 3 operators comparison.

benefit of $\mathrm{NBI}$ use. However, some operators may benefit from using this imaging technique, and it should be considered individually according to the preference and outcome from colonoscopies performed.

\section{Conflict of interest}

The authors declare no conflict of interest.

\section{References}

1. Torre LA, Siegel RL, Ward EM, Jemal A. Global cancer incidence and mortality rates and trends - an update. Cancer Epidemiol Biomarkers Prev 2016; 25: 16-27.

2. Winawer SJ, Zauber AG, Ho MN, et al. Prevention of colorectal cancer by colonoscopic polypectomy. The National Polyp Study Workgroup. N Engl J Med 1993; 329: 1977-81.

3. Kaminski MF, Regula J, Kraszewska E, et al. Quality indicators for colonoscopy and the risk of interval cancer. N Engl J Med 2010; 362: 1795-803.

4. Corley D, Jensen CD, Marks AR, et al. Adenoma detection rate and risk of colorectal cancer and death. N Engl J Med 2014; 370: 1298-306.
5. Van Rijn JC, Reitsma JB, Stoker J, et al. Polyp miss rate determined by tandem colonoscopy: a systematic review. Am J Gastroenterol 2006; 101: 343-50.

6. Omata F, Ohde S, Deshpande GA, et al. Image-enhanced, chromo, and cap-assisted colonoscopy for improving adenoma/ neoplasia detection rate: a systematic review and meta-analysis. Scand J Gastroenterol 2014; 49: 222-37.

7. Adler A, Aschenbeck J, Yenerim T, et al. Narrow-band versus white-light high definition television endoscopic imaging for screening colonoscopy: a prospective randomized trial. Gastroenterology 2009; 136: 410-6.

8. Inoue T, Murano M, Murano N, et al. Comparative study of conventional colonoscopy and pan-colonic narrow-band imaging system in the detection of neoplastic colonic polyps: a randomized, controlled trial. J Gastroenterol 2008; 43: 45-50.

9. Paggi S, Radaelli F, Amato A, et al. The impact of narrow-band imaging in screening colonoscopy: a randomized controlled trial. Clin Gastroenterol Hepatol 2009; 7: 1049-54.

10. East JE, Ignjatovic A, Suzuki N, et al. A randomized, controlled trial of narrow-band imaging vs. high-definition white light for adenoma detection in patients at high risk of adenomas. Color Dis 2012; 14: 771-8. 
11. Rex DK, Helbig CC. High yields of small and flat adenomas with high-definition colonoscopes using either white light or narrow-band imaging. Gastroenterology 2007; 133: 42-7.

12. Leung WK, Lo OS, Liu HS, et al. Detection of colorectal adenoma by narrow-band imaging (HQ190) vs. high-definition white light colonoscopy: a randomized controlled trial. Am J Gastroenterol 2014; 109: 855-63.

13. Kaltenbach T, Friedland S, Soetikno R. A randomised tandem colonoscopy trial of narrow-band imaging versus white light examination to compare neoplasia miss rates. Gut 2008; 57 : 1406-12.

14. Gross SA, Buchner AM, Crook JE, et al. A comparison of high definition-image enhanced colonoscopy and standard whitelight colonoscopy for colorectal polyp detection. Endoscopy 2011; 43: 1045-51.

15. Ikematsu H, Saito Y, Tanaka S, et al. The impact of narrow-band imaging for colon polyp detection: a multicenter randomized controlled trial by tandem colonoscopy. J Gastroenterol 2012; 47: 1099-107.

16. Sabbagh LC, Reveiz L, Aponte D, de Aguiar S. Narrow-band imaging does not improve detection of colorectal polyps when compared to conventional colonoscopy: a randomized controlled trial and meta-analysis of published studies. BMC Gastroenterol 2011; 11: 100.

17. Adler A, Pohl H, Papanikolaou IS, et al. A prospective randomised study on narrow-band imaging versus conventional colonoscopy for adenoma detection: does narrow-band imaging induce a learning effect? Gut 2008; 57: 59-64.

18. Dinesen L, Chua TJ, Kaffes AJ. Meta-analysis of narrow-band imaging versus conventional colonoscopy for adenoma detection. Gastrointest Endosc 2012; 75: 604-11.

19. Jin XF, Chai TH, Shi JW, et al. Meta-analysis for evaluating the accuracy of endoscopy with narrow-band imaging in detecting colorectal adenomas. J Gastroenterol Hepatol 2012; 27: 882-7.

20. Pasha SF, Leighton JA, Das A, et al. Comparison of the yield and miss rate of narrow-band imaging and white light endoscopy in patients undergoing screening or surveillance colonoscopy: a meta-analysis. Am J Gastroenterol 2012; 107: 363-70.

21. Singh H, Turner D, Xue L, et al. Risk of developing colorectal cancer following a negative colonoscopy examination. JAMA 2006; 295: 2366-73.

22. Bretthauer M, Kaminski MF, Løberg M, et al. Population-based colonoscopy screening for colorectal cancer. JAMA Intern Med 2016; 176: 894-902

23. Subramanian V, Mannath J, Hawkey CJ, Ragunath K. High definition colonoscopy vs. standard video endoscopy for the detection of colonic polyps: a meta-analysis. Endoscopy 2011; 43: 499-505.

24. Kaminski MF, Hassan C, Bisschops R, et al. Advanced imaging for detection and differentiation of colorectal neoplasia: European Society of Gastrointestinal Endoscopy (ESGE) Guideline. Endoscopy 2014; 46: 435-49.

Received: 29.10 .2017

Accepted: 2.02 .2018 